\title{
Erratum to: Comparative analysis of a wood-adhesive bondline
}

\author{
G. Modzel • F. A. Kamke $\cdot$ F. De Carlo
}

Published online: 18 June 2010

(C) Springer-Verlag 2010

\section{Erratum to: Wood Sci Technol \\ DOI 10.1007/s00226-010-0304-z}

The original version of this article contains a mistake. The presentation of this title was incorrect (colon instead of hyphen). The correct title should read:

Comparative analysis of a wood-adhesive bondline

The online version of the original article can be found under doi:10.1007/s00226-010-0304-z.

G. Modzel · F. A. Kamke $(\bowtie)$

Department of Wood Science and Engineering, Oregon State University,

119 Richardson Hall, Corvallis, OR 97331, USA

e-mail: fred.kamke@oregonstate.edu

F. De Carlo

Advanced Photon Source, Argonne National Laboratory,

9700 South Cass Avenue, APS-XFD/431, Argonne, IL 60439-4856, USA 